\title{
Diagnostic accuracy and yield of screening tests for atrial fibrillation in the family practice setting: a multicentre cohort study
}

\author{
F. Russell Quinn MD PhD, David J. Gladstone MD PhD, Noah M. Ivers MD PhD, \\ Roopinder K. Sandhu MD MPH, Lisa Dolovich MSc PharmD, Andrea Ling BSc, Juliet Nakamya PhD, \\ Chinthanie Ramasundarahettige MSc, Paul A. Frydrych MD, Sam Henein MD, Ken Ng MD, \\ Valerie Congdon MD, Richard V. Birtwhistle MD, Richard Ward MD, Jeffrey S. Healey MD MSc
}

Abstract

Background: Detection of undiagnosed or undertreated ("actionable") atrial fibrillation could increase the use of appropriate oral anticoagulant therapy and reduce the risk of stroke. We sought to compare newer screening technologies with a pulse-check for the detection of atrial fibrillation and to determine whether the detection of actionable atrial fibrillation increases the use of oral anticoagulant agents.

Methods: This prospective multicentre cohort study involved 22 primary care clinics. We recruited participants aged 65 years and older who were attending routine appointments. Each participant underwent 3 methods of screening: a 30-second radial pulse-check; single-lead electrocardiogram; and screening by blood pressure machine with atrial fibrillation detection algorithms. Participants who received a positive result on 1 or more test underwent 12-lead electrocardiogram with or withour 24-hour Holter. Screening tests were compared using the McNemar test. Participants with confirmed atrial fibrillation received follow-up at 90 days.

Results: The mean age of participants was $73.7( \pm 6.9)$ years, and $53.4 \%$ of participants were female. Of 2171 patients, we had data from all 3 screening tests for 2054 patients. Both single-lead electrocardiogram and the blood pressure device showed superior specificity compared with pulse-check $(p<0.001$ for each). Fifty-six patients $(2.7 \%)$ had confirmed atrial fibrillation: 12 patients had newly detected atrial fibrillation (none of the patients were using anticoagulation agents), and 44 patients had previously diagnosed atrial fibrillation (42 patients were receiving anticoagulant therapy, 2 were not). Thus, 14 patients had actionable atrial fibrillation (0.7\%). By 90 days, $77 \%$ of patients with actionable atrial fibrillation had started anticoagulant therapy.

Interpretation: Newer screening technologies showed superior specificity compared with a pulse-check. Screening detected undiagnosed or undertreated atrial fibrillation in $0.7 \%$ of participants, and $77 \%$ started appropriate anticoagulant therapy. Trial registration: ClinicalTrials.gov, no. NCT02262351.

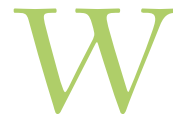

ithout treatment, atrial fibrillation increases the risk of stroke three- to five-fold and is independently associated with increased mortality, in addition to increased risk of heart failure, cognitive impairment and dementia. ${ }^{1-4}$ Therapy with orally administered anticoagulant agents can reduce the risk of stroke by twothirds and reduces mortality by one-quarter. ${ }^{5}$ Two key groups of undertreated patients are at risk of complications: patients with unrecognized ("silent") atrial fibrillation, and patients with atrial fibrillation that is not managed appropriately. These patients can be considered as having "actionable" atrial fibrillation, since their identification can lead to specific changes in therapy based on their risk profile.

Community screening for atrial fibrillation is feasible, cost-effective, and can result in the start of appropriate anti- coagulant therapy. ${ }^{6-15}$ In a systematic review of 30 studies reporting single time-point screening in a variety of settings,

Competing interests: Russell Quinn reports consulting fees from Boehringer Ingelheim, Servier and Bayer, and has research grants from Boehringer Ingelheim and Bayer. Richard Birtwhistle reports research funding from Eli Lilly, Shire Pharmaceuticals, Merck and Pfizer. Jeffrey Healey reports consulting fees from Bayer, Boehringer Ingelheim, Pfizer, Bristol-Myers Squib, and has research grants from Boehringer Ingelheim, Bayer, Pfizer and Bristol-Myers Squibb. No other competing interests were declared.

This article has been peer reviewed.

Correspondence to: F. Russell Quinn, frquinn@ucalgary.ca

CMAJ Open 2018. DOI:10.9778/cmajo.20180001 
the prevalence of newly diagnosed atrial fibrillation was $1.0 \%$, increasing to $1.4 \%$ for patients aged 65 years and older. ${ }^{14}$ Screening with a pulse-check in family practice clinics detects more new atrial fibrillation cases than routine care (incidence $1.63 \% / y r$ v. $1.04 \% / y r){ }^{6,9}$ The European Society of Cardiology atrial fibrillation guideline suggests that patients aged 65 years and older should undergo opportunistic screening for atrial fibrillation with a pulse-check, followed by electrocardiogram if irregularity is detected. ${ }^{4}$ This is the only current atrial fibrillation guideline to address the issue of screening. Newer technologies could improve the diagnostic accuracy and efficiency of screening, ${ }^{7,8,16}$ but few direct comparisons of screening methods exist. ${ }^{17}$ Our principal research objective was to determine whether newer technologies are more accurate than a pulsecheck for the detection and diagnosis of atrial fibrillation in family practice clinics. Our secondary objective was to determine whether changes in management occurred when actionable atrial fibrillation was detected.

\section{Methods}

\section{Setting}

We recruited 22 family practice clinics through the Primary Care Networks in Alberta, the University of Toronto Practice-Based Research Network in Ontario, and other sites known to the investigators. Potential sites completed questionnaires to determine prior research experience and availability of personnel to assist with study tasks. Training was performed by telephone and webinar presentations, with or without in-person visits.

\section{Study design, screening population and ethics approval}

This was a prospective multicentre cohort study. We recruited a convenience series of participants aged 65 years and older who were attending their family practice clinic for routine appointments in 2015 and 2016. Exclusion criteria were patients being unavailable for follow-up; having a cardiac implantable electronic device; inability to have a blood pressure cuff or electrocardiogram electrodes applied; or previous enrolment in the study. Patients with previously known atrial fibrillation were not excluded. Additional details are included as supplemental material (Appendix 1, available at www.cmajopen.ca/ content/6/3/E308/suppl/DC1). Participants provided informed consent. The trial was registered with ClinicalTrials.gov (registration no. NCT02262351).

\section{Atrial fibrillation screening protocol}

Trained staff performed opportunistic screening for each participant using 3 methods: a 30 -second radial pulsecheck; single-lead electrocardiogram (HeartCheck, CardioComm Solutions Inc.); and by blood pressure device (WatchBP Home A, Microlife AG). A pulse-check was deemed "positive" if any irregularity was found or if the heart rate was 110 beats/min or faster. Single-lead electrocardiograms were uploaded to a secure server, and the rhythm was determined by one of the study cardiologists (FRQ, RS or JH). Uncertain diagnoses were independently assessed by a second cardiologist, and any discrepancies were resolved by the third cardiologist. The blood pressure device takes 3 consecutive readings and reports "AFib" if all 3 readings have an irregular rhythm. Screening staff were blinded to previous diagnoses of atrial fibrillation, and staff who performed the pulse check were blinded to the results of the other 2 tests.

\section{Diagnosis of atrial fibrillation}

Participants who received a negative result on all 3 screening tests underwent no further testing or follow-up. All other participants (i.e., those who received a positive result on at least 1 test) underwent 12-lead electrocardiogram. If the electrocardiogram did not show atrial fibrillation, 24-hour Holter monitoring was performed. A diagnosis of "confirmed atrial fibrillation" required a 12-lead electrocardiogram showing atrial fibrillation for the entire tracing or a Holter showing more than 30 seconds of continuous atrial fibrillation. The performance of the screening tests was assessed relative to this gold standard. Participants with confirmed atrial fibrillation were deemed to have "actionable atrial fibrillation" if they were not currently taking an anticoagulant. This follows current Canadian Cardiovascular Society guidelines, which suggest anticoagulation therapy for all patients with atrial fibrillation aged 65 years and older. ${ }^{18}$ Patients with atrial fibrillation were considered to have "adequate anticoagulation" if they were taking a non-vitamin $\mathrm{K}$ antagonist oral anticoagulant or warfarin with more than $65 \%$ time in the therapeutic range. Patients with atrial fibrillation were identified to their family physician, and treatment decisions were at these family physicians' discretion.

\section{Clinical data collection and follow-up}

Baseline demographic and clinical data included risk factors for atrial fibrillation and thromboembolism. Data from patients with confirmed atrial fibrillation included current medications and time in therapeutic range (from their most recent 6 international normalized ratio results) for those taking warfarin. Patients with confirmed atrial fibrillation received follow-up after $90( \pm 14)$ days to document clinical status, medication, heart rate, blood pressure and health care use.

\section{Statistical analysis}

Only patients with 1 or more positive test result had confirmatory testing, so it is not possible to estimate the overall sensitivity or specificity for atrial fibrillation detection for each test. However, using discordant results between 2 tests, it is possible to test for differences in sensitivity or specificity using the McNemar test of equality of proportions, as outlined by Schatzkin and colleagues. ${ }^{19}$ Sample size calculations can also be performed using this method (Appendix 1). ${ }^{19-22}$ Calculations used a paired-study design (single-lead electrocardiogram and blood pressure device compared separately with pulse-check) with a 2 -sided $\alpha$ of 0.025 for multiple compari- 
sons. Only data from patients who had usable data from the 3 screening tests and who attended confirmatory testing were included in the analysis.

The prespecified primary outcome was the comparison of sensitivity and specificity between screening tests using the $\mathrm{McNemar}$ method. The relative false-positive rates for single-lead electrocardiogram and blood pressure device compared with pulse-check were calculated as outlined by Chock and colleagues. ${ }^{23}$ Prespecified secondary outcomes included heart rate and blood pressure at baseline and at 90 days for patients with actionable atrial fibrillation; and prescription rates at 90 days for anticoagulant agents and rateor rhythm-control drugs. Continuous variables are presented as mean and standard deviation (SD), or median and interquartile range (IQR), as needed. Categorical variables were compared using a $\chi^{2}$ test and continuous variables using a $t$ test. Data at baseline and follow-up were compared using paired $t$ tests for continuous variables and McNemar test for categorical variables. Analyses were performed using SAS version 9.4.

\section{Ethics approval}

The following Research Ethics Boards approved the study: Hamilton Integrated Research Ethics Board; University of Alberta; University of Calgary; Women's College Hospital; Sunnybrook Health Sciences Centre; Queen's University.

\section{Results}

\section{Demographics of the screened population}

Figure 1 shows the flow of participants through the study, including attendance rates for confirmatory testing. A total of 2171 participants were enrolled, with a final study population of 2054. The median number of patients enrolled at each site was 47 (IQR 21-151). Seven sites were in municipalities with a population of less than 25000 people, and the remainder of sites were in larger urban centres. Table 1 summarizes patient characteristics at baseline. There was a high prevalence of hypertension and diabetes among participants, with lower rates of prior stroke, transient ischemic attack, systemic embolism, myocardial infarction and heart failure.

\section{Screening results}

Figure 1 and Table 2 summarize the results of screening, including true-positives, false-positives, and the positive predictive value of each test. One or more test showed a positive result for 168 participants (8.2\%). Only 1 participant had a positive pulse-check criterion of a heart rate faster than 110 beats/min; the remainder of the positive pulse-check results were for irregularity. The median time from a positive result to 12 -lead electrocardiogram was 1 (IQR $0-140) \mathrm{h}$; the median time to Holter monitor was 27 (IQR 20-39) d. In the primary analysis (Appendix 1), both single-lead electrocardiogram and the blood pressure device had higher specificity than pulse-check for the detection of atrial fibrillation $(p<$ $0.001)$.

\section{Characteristics of patients with atrial fibrillation detected on screening}

A total of 56 patients had confirmed atrial fibrillation, giving an overall prevalence of screen-detected atrial fibrillation of $2.7 \%$. Patients with confirmed atrial fibrillation (Table 1) were older, more often male, had higher body mass index and higher incidence of comorbidities, including heart failure, hypertension, valvular heart disease and previous cardiac surgery. Among patients with atrial fibrillation, $85.7 \%$ had a thromboembolism risk score of 3 or greater (points for congestive heart failure, hypertension, age $\geq 75 \mathrm{yr}$ [doubled], diabetes mellitus, stroke [doubled], presence of vascular disease, age 65-74 yr, female sex). Resting heart rate was higher for patients with atrial fibrillation compared with those who did not have atrial fibrillation, and systolic blood pressure was lower. Of the 56 patients with atrial fibrillation, it was a known diagnosis for 44 patients and a new diagnosis for 12 patients $(2.1 \%$ and $0.6 \%$ of the study population, respectively). There was no significant difference in demographics, heart rate or blood pressure between patients with newly diagnosed and known atrial fibrillation (Appendix 1). Fortytwo $(95.5 \%)$ of the patients with known atrial fibrillation, but none of the patients with newly diagnosed atrial fibrillation, were taking anticoagulant agents at baseline. Thus, 14 patients had actionable atrial fibrillation $(0.7 \%$ of the study population). Twenty-two of the 56 patients with atrial fibrillation were either not taking anticoagulants or had suboptimal warfarin control (1.1\% of the study population).

\section{Health care use and clinical data for patients with atrial fibrillation}

Follow-up data were obtained for 51 of the 56 patients with confirmed atrial fibrillation, including 13 patients who had actionable atrial fibrillation (Table 3). At 90 days, 48 of the 51 patients (94\%) were receiving anticoagulant therapy, mainly through increased prescription of non-vitamin $\mathrm{K}$ antagonist oral anticoagulant agents. The proportion of patients with "adequate anticoagulation" increased from $63 \%$ at baseline to $82 \%(p=0.024)$, and from $0 \%$ to $77 \%$ among the 13 patients with actionable atrial fibrillation. Prescription rates for antiplatelet agents and rate- or rhythm-control agents did not differ between baseline and follow-up, nor were there significant differences in heart rate or blood pressure. Clinical events and health care use data are presented in Table 4.

\section{Interpretation}

Single-lead electrocardiogram and the blood pressure device we used had superior specificity to pulse-check for the detection of atrial fibrillation, with $72 \%$ and $48 \%$ fewer falsepositive results, respectively. Furthermore, most of the patients for which actionable atrial fibrillation as detected were given a prescription for anticoagulant agents within 90 days, with 8 of the 10 patients starting anticoagulanttherapy for the first time being given a non-vitamin $\mathrm{K}$ antagonist. This substantially increased the overall quality of anticoagulation from baseline to 90 days. 


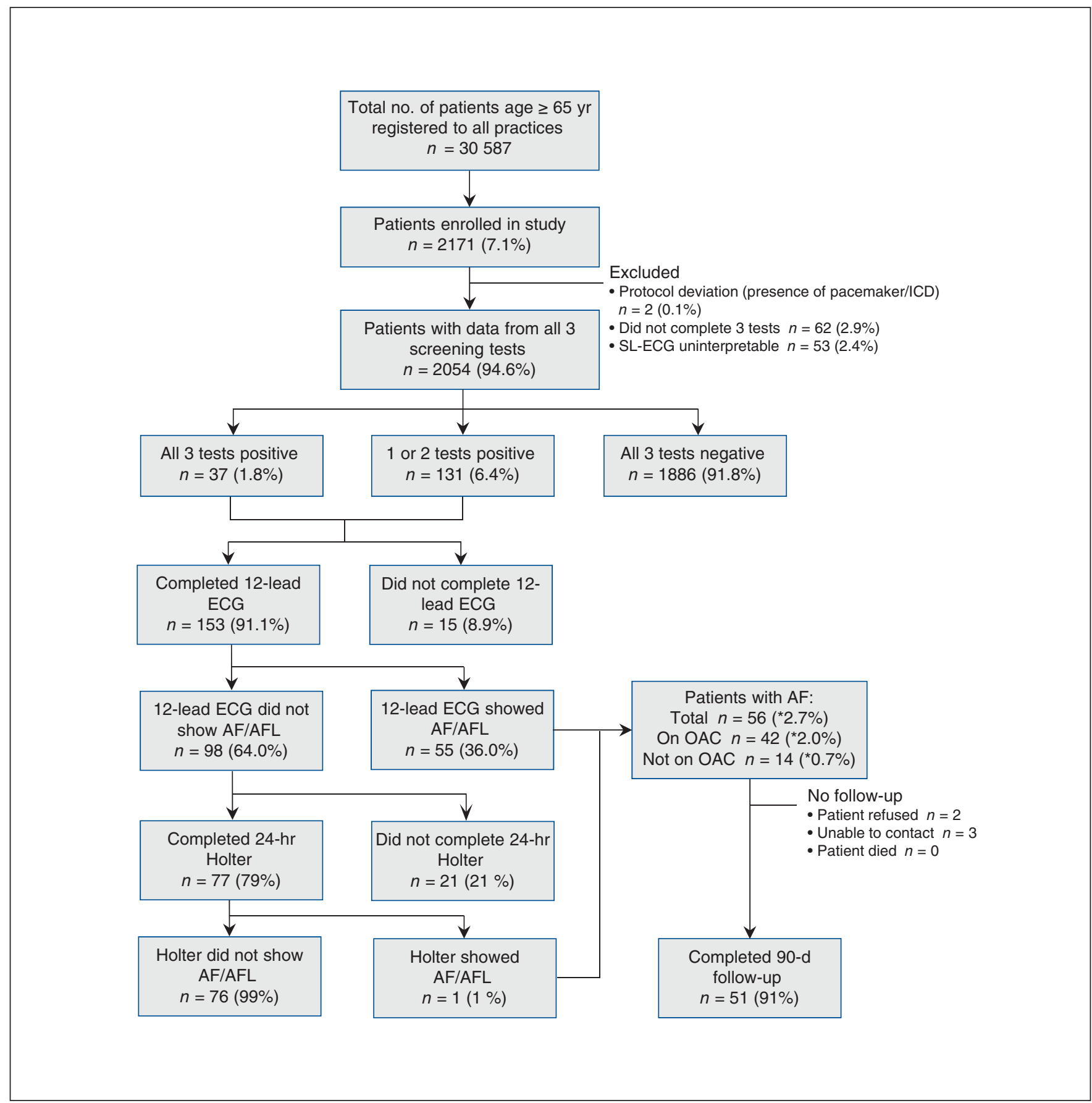

Figure 1: Flow of patients through the study. Percentages in parentheses relate to numbers in preceding level, with the exception of those marked by an asterisk $\left({ }^{*}\right)$, which indicates that the percentage was calculated based on the 2054 patients with data from all 3 screening tests. Note: $\mathrm{AF}=$ atrial fibrillation, $\mathrm{AFL}=$ atrial flutter, $\mathrm{ECG}=$ electrocardiogram, $\mathrm{ICD}=$ implantable cardioverter defibrillator, $\mathrm{OAC}=$ oral anticoagulant agent, SL-ECG = single-lead electrocardiogram.

We directly compared pulse-checks with newer technologies for the detection of atrial fibrillation in unselected older adults in the primary care setting. Previous indirect comparisons, using systematic reviews of earlier studies, have suggested comparable sensitivity for pulse-check, blood pressure devices and single-lead electrocardiogram, with superior specificity for the latter 2 tests, ${ }^{15,24}$ a finding confirmed here. In a small study that involved selected patients, pulse palpation by a nurse had a lower specificity than single-lead electrocardiograms interpreted by a nurse or general practitioner. ${ }^{25}$ In another study, the diagnostic accuracy of a blood pressure device was similar to that of electrocardiograms generated by 2 different single-lead devices and interpreted by a cardiologist, but no comparison with a pulse-check was done. ${ }^{17} \mathrm{~A}$ pulse-check is a simple screening test, with reasonable sensitivity that requires few resources. Whether the improved 
Table 1: Baseline characteristics of patients, stratified by presence or absence of confirmed atrial fibrillation

\begin{tabular}{|c|c|c|c|c|}
\hline \multirow[b]{3}{*}{ Characteristic } & \multicolumn{3}{|c|}{ No. $(\%)^{\star}$} & \multirow{3}{*}{$\begin{array}{c}p \text { value } \\
\text { Atrial fibrillation } \\
\text { confirmedt: } \\
\text { yes v. no }\end{array}$} \\
\hline & \multirow{2}{*}{$\begin{array}{c}\text { Overall } \\
\text { population } \\
n=2054\end{array}$} & \multicolumn{2}{|c|}{$\begin{array}{l}\text { Atrial fibrillation confirmed after } \\
\text { screeningt: }\end{array}$} & \\
\hline & & $\begin{array}{c}\text { Yes } \\
n=56\end{array}$ & $\begin{array}{c}\text { No } \\
n=1998\end{array}$ & \\
\hline Age, yr, mean \pm SD & $73.7 \pm 6.9$ & $78.2 \pm 7.0$ & $73.6 \pm 6.8$ & $<0.001$ \\
\hline Male sex & $958(46.6)$ & $35(63)$ & $923(46.2)$ & 0.016 \\
\hline White ethnicity & $1783(86.8)$ & $53(95)$ & $1730(86.6)$ & 0.079 \\
\hline Body mass index $\left(\mathrm{kg} / \mathrm{m}^{2}\right)$, mean $\pm \mathrm{SD}$ & $28.3 \pm 5.6$ & $29.9 \pm 6.5$ & $28.2 \pm 5.5$ & 0.029 \\
\hline \multicolumn{5}{|l|}{ Comorbidity } \\
\hline Heart failure & $53(2.6)$ & $14(25)$ & $39(2.0)$ & $<0.001$ \\
\hline Hypertension & $1214(59.1)$ & $43(77)$ & $1171(58.6)$ & 0.006 \\
\hline Diabetes & $574(27.9)$ & $20(36)$ & $554(27.7)$ & 0.19 \\
\hline Previous stroke, transient ischemic attack, or systemic embolism & $149(7.3)$ & $8(14)$ & $141(7.1)$ & 0.040 \\
\hline Previous myocardial infarction & $149(7.3)$ & $7(13)$ & $142(7.1)$ & 0.13 \\
\hline Peripheral vascular disease or aortic atheroma & $86(4.2)$ & $5(9)$ & $81(4.1)$ & 0.073 \\
\hline Valvular heart disease & $42(2.0)$ & $8(14)$ & $34(1.7)$ & $<0.001$ \\
\hline Previous cardiac surgery & $200(9.7)$ & $15(27)$ & $185(9.3)$ & $<0.001$ \\
\hline Current or former smoker & $1036(50.4)$ & $35(63)$ & $1001(50.1)$ & 0.067 \\
\hline $\mathrm{CHA}_{2} \mathrm{DS}_{2}-\mathrm{VASc}$ score $=1$ & $173(8.4)$ & $2(4)$ & $171(8.6)$ & 0.23 \\
\hline $\mathrm{CHA}_{2} \mathrm{DS}_{2}$-VASc score $=2$ & $567(27.6)$ & $6(11)$ & $561(28.1)$ & 0.004 \\
\hline $\mathrm{CHA}_{2} \mathrm{DS}_{2}$-VASc score $\geq 3$ or higher & $1314(64.0)$ & $48(86)$ & $1266(63.4)$ & $<0.001$ \\
\hline Heart rate (beats/min), mean $\pm \mathrm{SD}$ & $70.5 \pm 11.80$ & $76.3 \pm 11.43$ & $70.4 \pm 11.78$ & $<0.001$ \\
\hline Systolic blood pressure, $\mathrm{mm} \mathrm{Hg}$, mean $\pm \mathrm{SD}$ & $137.9 \pm 16.87$ & $133.2 \pm 17.18$ & $138.0 \pm 16.84$ & 0.035 \\
\hline Diastolic blood pressure, $\mathrm{mm} \mathrm{Hg}$, mean $\pm \mathrm{SD}$ & $76.4 \pm 9.77$ & $77.9 \pm 11.87$ & $76.3 \pm 9.71$ & 0.33 \\
\hline
\end{tabular}

specificity of single-lead electrocardiograms and blood pressure devices translates into superior cost-effectiveness requires further analysis and will be presented in a separate study.

The prevalence of newly diagnosed atrial fibrillation $(0.6 \%)$ in our overall study population was fairly low, although this result was similar to that from other community studies that used single time-point screening. In a study by Svennberg and colleagues, 7173 patients aged 75 or 76 years underwent screening with intermittent single-lead electrocardiogram. ${ }^{26}$ Previously unknown atrial fibrillation was found in $0.5 \%$ of the patients during their first electrocardiogram. Kearley and colleagues identified newly diagnosed atrial fibrillation in $1.2 \%$ of 1000 patients aged 75 years and older using 12-lead electrocardiogram. ${ }^{17}$

\section{Limitations}

Our study did not exclude patients with previously known atrial fibrillation. Although it may appear unnecessary to "rediagnose" these patients, this approach can be a valuable way of identifying patients who are not receiving appropriate anticoagulation, triggering a review of their therapy. ${ }^{26}$ Indeed, we found a high level of baseline anticoagulant use in this population $(95.5 \%)$, in contrast to other reports where rates of anticoagulant use were typically $50 \%-65 \% .{ }^{27-30}$ Some reports have suggested that anticoagulant use is increasing among patients with atrial fibrillation in the community, partly through increased uptake of non-vitamin K antagonists. ${ }^{31-33}$ We cannot exclude some sampling bias in our study: participating sites may have been more focused on atrial fibrillation management and participating patients may have been more motivated to have an active role in their health care. Screening populations with lower baseline rates of anticoagulant use would reduce the number of patients needed to screen to detect a single case of actionable atrial fibrillation. Identification of patients with actionable atrial fibrillation did lead to a marked increase in anticoagulant use at 90 days.

Given the nature of busy family practice clinics, we were unable to recruit a consecutive series of eligible participants, 
Table 2: Practical characteristics and performance of the 3 screening tests

\begin{tabular}{|c|c|c|c|c|c|c|c|}
\hline \multirow[b]{2}{*}{ Screening test } & \multirow{2}{*}{$\begin{array}{c}\text { Time taken for test, } \mathrm{s}, \\
\text { mean } \pm \text { SD }\end{array}$} & \multicolumn{2}{|c|}{$\begin{array}{c}\text { Screening test result } \\
\text { no. }(\%)\end{array}$} & \multirow{2}{*}{$\begin{array}{l}\text { True positive } \\
\text { (atrial fibrillation } \\
\text { confirmed)* }\end{array}$} & \multirow{2}{*}{$\begin{array}{l}\text { False positive } \\
\text { (atrial fibrillation } \\
\text { excluded)* }\end{array}$} & \multirow{2}{*}{$\begin{array}{c}\text { Positive } \\
\text { predictive value } \\
\%(95 \% \mathrm{Cl})\end{array}$} & \multirow{2}{*}{$\begin{array}{c}\text { Relative false } \\
\text { positive rate } \\
\text { compared } \\
\text { with } \\
\text { pulse-check }\end{array}$} \\
\hline & & Pos. & Neg. & & & & \\
\hline $\begin{array}{l}\text { Pulse-check } \\
n=2054\end{array}$ & $42.1 \pm 22.5$ & $118(5.7)$ & $1936(94.3)$ & 45 & 65 & $40.9(31.7-50.1)$ & - \\
\hline $\begin{array}{l}\text { Single-lead } \\
\text { ECG } \\
n=2054\end{array}$ & $128.2 \pm 82.0$ & $78(3.8)$ & $1976(96.2)$ & 51 & 18 & 73.9 (63.6-84.3) & 0.28 \\
\hline $\begin{array}{l}\text { Blood } \\
\text { pressure } \\
n=2054\end{array}$ & $194.8 \pm 71.5$ & 79 (3.8) & 1975 (96.2) & 39 & 34 & $53.4(42.0-64.9)$ & 0.52 \\
\hline
\end{tabular}

Table 3: Baseline and 90-day data for patients with screen-detected atrial fibrillation who completed follow-up

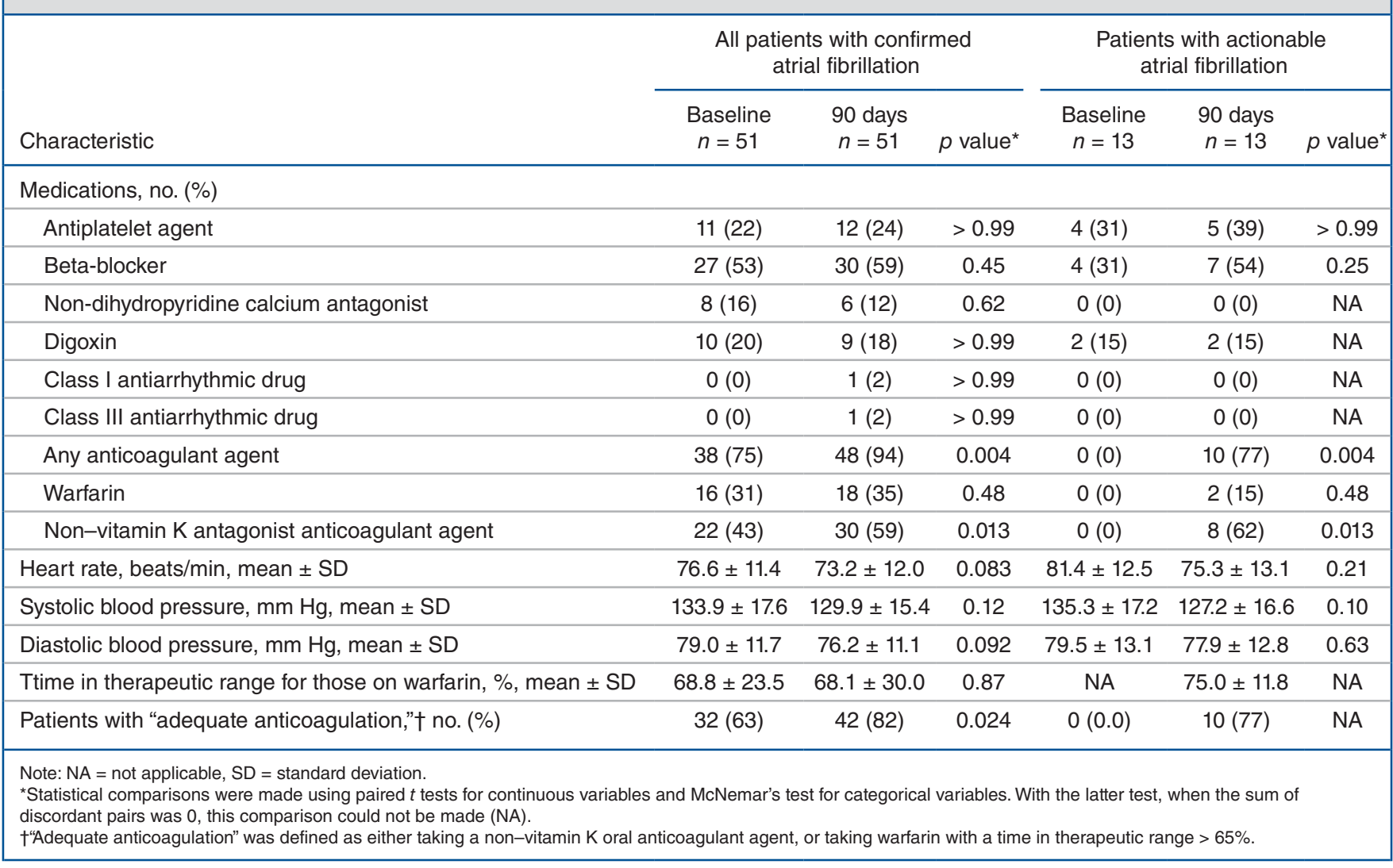

thus our convenience series could have resulted in selection bias. Because participants who showed a negative result on all 3 tests did not undergo further testing, the true prevalence of atrial fibrillation was not determined, nor could we calculate the true sensitivity or specificity of each test. In addition, owing to a lack of power, we were unable to compare the sensitivity of the tests for the detection of atrial fibrillation. Previous reports have suggested a high sensitivity (>92\%) and specificity (> 89\%) for the types of devices we used. ${ }^{16,17}$ No single screening method detected atrial fibrillation in all 56 patients with confirmed atrial fibrillation: pulse-check, singlelead electrocardiogram and blood pressure device missed 11, 5 and 17 patients, respectively. Screening at a single time point is a practical approach, but will miss many patients with paroxysmal atrial fibrillation, underestimating the true prevalence in the population. Repeated screening or more prolonged 
Table 4: Clinical events and health care use for patients with atrial fibrillation detected on screening who completed 90-day follow-up

\begin{tabular}{|lcc|}
\hline Clinical event & $\begin{array}{c}\text { Confirmed atrial fibrillation, no. (\%)* } \\
n=51\end{array}$ & $\begin{array}{c}\text { Actionable atrial fibrillation, no. (\%)* } \\
n=13\end{array}$ \\
\hline Stroke, transient ischemic attack, or systemic embolism & $0(0)$ & $0(0)$ \\
\hline Myocardial infarction & $0(0)$ & $0(0)$ \\
\hline Heart failure with admission to hospital & $1(2)$ & $0(0)$ \\
\hline Major bleed & $0(0)$ & $0(0)$ \\
\hline Death & $0(0)$ & $0(0)$ \\
\hline Health care use & & $1(0)$ \\
\hline Emergency department visit & $10(20)$ & 1 \\
\hline No. of emergency department visits & 14 & $0(0)$ \\
\hline Admission to hospital & $4(8)$ & 0 \\
\hline No. of admissions & 5 & $10(77)$ \\
\hline Family physician visits & $36(71)$ & 26 \\
\hline No. of family physician visits & 84 & $4(31)$ \\
\hline Specialty clinic visits & $15(30)$ & 5 \\
\hline No. of specialty clinic visits & 17 & 5 \\
\hline
\end{tabular}

monitoring will detect more cases of (mainly paroxysmal) atrial fibrillation. ${ }^{26,34}$ In the study by Svennberg and colleagues, repeated intermittent single-lead electrocardiogram monitoring over 2 weeks increased the prevalence of newly detected atrial fibrillation from $0.5 \%$ (on initial electrocardiogram) to $3.0 \% .{ }^{26}$ However, there is some evidence that those with nonparoxysmal atrial fibrillation carry higher thromboembolic risk, even with a similar thromboembolic risk score. ${ }^{35,36}$ Thus, detection of non-paroxysmal atrial fibrillation may identify those who stand to benefit more from appropriate anticoagulation therapy. Finally, screening in our study was performed opportunistically (i.e., only patients attending their family practice clinic were included). This approach follows the European Society of Cardiology recommendations, ${ }^{4}$ but would not identify actionable atrial fibrillation among patients who did not attend their clinic. However, in a cluster randomized study, Fitzmaurice and colleagues found no difference in new atrial fibrillation detection between an opportunistic approach and a systematic approach of invitation for 12-lead electrocardiogram (1.64\% v. $1.62 \%$ per year, $p=$ nonsignificant). ${ }^{6}$ Both approaches appear to be cost-effective,, 90 and the preferred method would likely depend on local infrastructure and available health care personnel.

\section{Conclusion}

Both single-lead electrocardiogram and blood pressure devices showed superior specificity than a manual pulse-check for the detection of atrial fibrillation. Most patients with actionable atrial fibrillation detected on screening started to receive appropriate anticoagulant therapy within 90 days. Multiple studies have now shown that screening for atrial fibrillation in the community can identify patients with undertreated cases. It remains unknown whether screening for atrial fibrillation translates to fewer strokes and other complications.

\section{References}

1. Andersson T, Magnuson A, Bryngelsson I-L, et al. All-cause mortality in 272 186 patients hospitalized with incident atrial fibrillation 1995-2008: a Swedish nationwide long-term case-control study. Eur Heart 7 2013;34:1061-7.

2. Davis RC, Hobbs FD, Kenkre JE, et al. Prevalence of atrial fibrillation in the general population and in high-risk groups: the ECHOES study. Europace 2012;14:1553-9.

3. Kalantarian S, Stern TA, Mansour M, et al. Cognitive impairment associated with atrial fibrillation: a meta-analysis. Ann Intern Med 2013;158:338-46.

4. Kirchhof P, Benussi S, Kotecha D, et al. 2016 ESC Guidelines for the management of atrial fibrillation developed in collaboration with EACTS. Eur Heart 7 2016;37:2893-962.

5. Hart RG, Pearce LA, Aguilar MI. Meta-analysis: antithrombotic therapy to prevent stroke in patients who have nonvalvular atrial fibrillation. Ann Intern Med 2007; 146:857-67.

6. Fitzmaurice DA, Hobbs FD, Jowett $S$, et al. Screening versus routine practice in detection of atrial fibrillation in patients aged 65 or over: cluster randomised controlled trial. BM7 2007;335:383-6.

7. Chan N-Y, Choy C-C. Screening for atrial fibrillation in 13122 Hong Kong citizens with smartphone electrocardiogram. Heart 2017;103:24-31.

8. Lowres N, Neubeck L, Salkeld G, et al. Feasibility and cost-effectiveness of stroke prevention through community screening for atrial fibrillation using iPhone ECG in pharmacies. The SEARCH-AF study. Thromb Haemost 2014; 111:1167-76.

9. Hobbs FD, Fitzmaurice DA, Mant J, et al. A randomised controlled trial and cost-effectiveness study of systematic screening (targeted and total population screening) versus routine practice for the detection of atrial fibrillation in people aged 65 and over. The SAFE study. Health Technol Assess 2005;9:iii-iv, :ix-x,1-74.

10. Aronsson M, Svennberg E, Rosenqvist M, et al. Cost-effectiveness of mass screening for untreated atrial fibrillation using intermittent ECG recording. Europace 2015;17:1023-9.

11. Maeda K, Shimbo T, Fukui T. Cost-effectiveness of a community-based screening programme for chronic atrial fibrillation in Japan. 7 Med Screen 2004;11:97-102.

12. Deif B, Lowres N, Freedman SB. Screening for atrial fibrillation above age 65 detects an asymptomatic subset at high risk of stroke. Int 7 Cardiol 2013; 164:371-2.

13. Engdahl J, Andersson L, Mirskaya M, et al. Stepwise screening of atrial fibrillation in a 75-year-old population: implications for stroke prevention. Circulation 2013;127:930-7.

14. Lowres N, Neubeck L, Redfern J, et al. Screening to identify unknown atrial fibrillation. A systematic review. Thromb Haemost 2013;110:213-22.

15. Welton NJ, McAleenan A, Thom HH, et al. Screening strategies for atrial fibrillation: a systematic review and cost-effectiveness analysis. Health Technol Assess 2017;21:1-236.

16. Quinn FR, Gladstone D. Screening for undiagnosed atrial fibrillation in the community. Curr Opin Cardiol 2014;29:28-35. 
17. Kearley K, Selwood M, Van den Bruel A, et al. Triage tests for identifying atrial fibrillation in primary care: a diagnostic accuracy study comparing singlelead ECG and modified BP monitors. BM7 Open 2014;4:e004565.

18. Verma A, Cairns JA, Mitchell LB, et al. 2014 focused update of the Canadian Cardiovascular Society Guidelines for the management of atrial fibrillation. Can 7 Cardiol 2014;30:1114-30.

19. Schatzkin A, Connor RJ, Taylor PR, et al. Comparing new and old screening tests when a reference procedure cannot be performed on all screenees. Example of automated cytometry for early detection of cervical cancer. Am 7 Epidemiol 1987; 125:672-8.

20. Beam CA. Strategies for improving power in diagnostic radiology research. A7R Am F Roentgenol 1992;159:631-7.

21. Obuchowski NA. Sample size calculations in studies of test accuracy. Stat Methods Med Res 1998;7:371-92.

22. Connor RJ. Sample size for testing differences in proportions for the pairedsample design. Biometrics 1987;43:207-11.

23. Chock C, Irwig L, Berry G, et al. Comparing dichotomous screening tests when individuals negative on both tests are not verified. 7 Clin Epidemiol 1997;50:1211-7.

24. Taggar JS, Coleman T, Lewis S, et al. Accuracy of methods for detecting an irregular pulse and suspected atrial fibrillation: a systematic review and metaanalysis. Eur 7 Prev Cardiol 2016;23:1330-8.

25. Somerville S, Somerville J, Croft P, et al. Atrial fibrillation: a comparison of methods to identify cases in general practice. Br 7 Gen Pract 2000;50:727-9.

26. Svennberg E, Engdahl J, Al-Khalili F, et al. Mass screening for untreated atrial fibrillation: the STROKESTOP Study. Circulation 2015;131:2176-84.

27. Sandhu RK, Bakal JA, Ezekowitz JA, et al. Risk stratification schemes, anticoagulation use and outcomes: the risk-treatment paradox in patients with newly diagnosed non-valvular atrial fibrillation. Heart 2011;97:2046-50.

28. Andersson P, Londahl M, Abdon NJ, et al. The prevalence of atrial fibrillation in a geographically well-defined population in northern Sweden: implications for anticoagulation prophylaxis. F Intern Med 2012;272:170-6.

29. Ogilvie IM, Newton N, Welner SA, et al. Underuse of oral anticoagulants in atrial fibrillation: a systematic review. Am 7 Med 2010;123:638-45.e4.

30. Cowan C, Healicon R, Robson I, et al. The use of anticoagulants in the management of atrial fibrillation among general practices in England. Heart 2013; 99:1166-72.

31. Zimny M, Blum S, Ammann P, et al. Uptake of non-vitamin K antagonist oral anticoagulants in patients with atrial fibrillation - a prospective cohort study. Swiss Med Wkly 2017;147:w14410.

32. Suzuki S, Otsuka T, Sagara K, et al. Nine-year trend of anticoagulation use, thromboembolic events, and major bleeding in patients with non-valvular atrial fibrillation - Shinken Database analysis. Circ 7 2016;80:639-49.

33. Camm AJ, Accetta G, Ambrosio G, et al. Evolving antithrombotic treatment patterns for patients with newly diagnosed atrial fibrillation. Heart 2017; 103:307-14.

34. Healey JS, Connolly SJ, Gold MR, et al. Subclinical atrial fibrillation and the risk of stroke. N Engl 7 Med 2012;366:120-9.

35. Steinberg BA, Hellkamp AS, Lokhnygina Y, et al. Higher risk of death and stroke in patients with persistent vs. paroxysmal atrial fibrillation: results from the ROCKET-AF Trial. Eur Heart 7 2015;36:288-96.

36. Vanassche T, Lauw MN, Eikelboom JW, et al. Risk of ischaemic stroke according to pattern of atrial fibrillation: analysis of 6563 aspirin-treated patients in ACTIVE-A and AVERROES. Eur Heart 7 2015;36:281-7a.

Affiliations: Libin Cardiovascular Institute of Alberta (Quinn), University of Calgary, Calgary, Alta.; Division of Neurology (Gladstone), Sunnybrook Health Sciences Centre and Sunnybrook Research Institute, and Department of Medicine, University of Toronto, Toronto, Ont.; Department of Family and Community Medicine (Ivers), Women's College Hospital - University of Toronto, Toronto, Ont.; University of Alberta (Sandhu), Edmonton, Alta.; Department of Family Medicine (Dolovich), McMaster University, Hamilton, Ont.; Population Health Research Institute (Ling, Nakamya, Ramasundarahettige, Healey), McMaster University, Hamilton, Ont.; Mount Dennis Weston Health Centre (Frydrych), Toronto, Ont.; SKDS Research Inc. (Henein), Newmarket, Ont.; Ken Ng Family Practice (Ng), Markham, Ont.; Foothills Family Medical Centre (Congdon), Black Diamond, Alta.; Department of Family Medicine (Birtwhistle), Queen's University, Kingston, Ont.; Crowfoot Village Family Practice (Ward), Calgary, Alta.

Contributors: Russell Quinn, Juliet Nakamya and Andrea Ling had full access to all of the the data and take responsibility for its integrity the accu- racy of the analysis. Russell Quinn, David Gladstone, Noah Ivers, Roopinder Sandhu, Lisa Dolovich and Jeffrey Healey contributed to concept and design. All of the authors contributed to the acquisition, analysis or interpretation of the data. Russell Quinn, Juliet Nakamya and Jeffrey Healey drafted the manuscript. All of the authors critically revised the manuscript for important intellectual content, approved the final version of the manuscript for publication and agreed to act as guarantors of the results.

Funding: The Program for the Identification of "Actionable" Atrial Fibrillation in the Family Practice Setting (PIAAF-FP) study was supported by the Canadian Stroke Prevention Intervention Network (C-SPIN), Boehringer Ingelheim and in-kind support from CardioComm and ManthaMed. Roopinder Sandhu received a grant from the University Hospital Foundation. Jeffrey Healey has a Personnel Award from the Heart and Stroke Foundation, Ontario provincial office (MC7450). Noah Ivers holds a Canadian Institutes of Health Research New Investigator Award in Community Based Primary Health Care and a Clinician Scientist award from the Department of Family and Community Medicine, University of Toronto. This research is supported in part by the University of Toronto Practice-Based Research Network (UTOPIAN), and by the Camrose Primary Care Network. David Gladstone received a Mid-Career Award from the Heart and Stroke Foundation and Eaton Scholar Award from the University of Toronto Department of Medicine, and research support from the Tory family and Sunnybrook Department of Medicine.

Drs. Quinn, Gladstone, Ivers, Sandhu, Dolovich, Ling, Nakamya, Ramasundarahettige and Healey are members of C-SPIN, and this network played an advisory role in the design and conduct of the study, interpretation of the data, and review of the manuscript. Boehringer Ingelheim, CardioComm and ManthaMed had no role in the design and conduct of the study; collection, management, analysis and interpretation of the data; preparation, review or approval of the manuscript; and decision to submit the manuscript for publication.

Any opinions, findings, and conclusions or recommendations expressed in this material are those of the authors and do not necessarily reflect the views of UTOPIAN.

Acknowledgements: The authors thank the patients who participated in the study, the staff and clinicians in the study practices, and the following sites and individuals for the recruitment and screening of participants: Mount Dennis Weston Health Centre, Toronto, Ont. (L. Frydrych); SKDS Research Inc., Newmarket, Ont. (H. Lappala); Ken Ng Family Practice, Markham, Ont.; Foothills Family Medical Centre, Black Diamond, Alta.; Queen's Family Health Team, Kingston, Ont.; Sunnybrook Health Sciences Centre, Toronto, Ont. (J. Charles, S. Syed); Kirkfield Medical Centre, Kirkfield, Ont. (K. Koprowicz); Women's College Hospital, Toronto, Ont.; Camrose Primary Care Network/Smith Clinic, Camrose, Alta. (C. Nichol, M. Rathnavalu); Crowfoot Village Family Practice, Calgary, Alta; Allin Clinic, Edmonton, Alta. (D. Moores, A. Tewelde); The Port Arthur Clinic Research Program, Thunder Bay, Ont. (R. Allison, M. Hogard); Hamilton Medical Clinic, Hamilton, Ont. (D. Zizzo, H. Blackwood); Royal Alexandra Family Medicine Centre, Edmonton, Alta (D. Moores, G. Burns); Eastwood Clinic, Edmonton, Alta (D. Moores, K. McKenna); Village Health Centre, Toronto, Ont. (M. Waxman, L. Bennett); Mark Robertson Family Practice, Owen Sound, Ont. (M. Robertson, B. Conti); Abbottsfield Medical Clinic, Edmonton, Alta (M. Wong); Wild Rose Medical Centre, Olds, Alta. (K. Dykin, C. Simon); Greenwood Family Physicians, Sundre, Alta. (E. Landsbergen, D. Hopton); Alberta Clinical Research Inc., Edmonton, Alta. (A. Kelly, A. Reyes); Sameh Fikry Medicine Professional Corporation, Waterloo, Ont. (W. Basily). The authors also thank Tammy Sovereign for her assistance with running the study, and Dr. D. George Wyse and Dr. Robert S. Sheldon for reviewing earlier versions of the manuscript and providing helpful suggestions for revisions.

Supplemental information: For reviewer comments and the original submission of this manuscript, please see www.cmajopen.ca/content/6/3/ E308/suppl/DC1. 